\title{
The current status of chronic obstructive pulmonary disease awareness, treatments, and plans for improvement in South Korea: a narrative review
}

\author{
Yong Bum Park ${ }^{1}$ Kwang Ha Yoo ${ }^{2}$ \\ ${ }^{1}$ Division of Pulmonary, Allergy and Critical Care Medicine, Department of Internal Medicine, Hallym University, Kangdong Sacred Heart \\ Hospital, Seoul, Korea; ${ }^{2}$ Division of Pulmonary, Allergy and Critical Care Medicine, Department of Internal Medicine, Konkuk University School of \\ Medicine, Seoul, Korea \\ Contributions: (I) Conception and design: Both authors; (II) Administrative support: Both authors; (III) Provision of study materials or patients: \\ Both authors; (IV) Collection and assembly of data: Both authors; (V) Data analysis and interpretation: Both authors; (VI) Manuscript writing: Both \\ authors; (VII) Final approval of manuscript: Both authors. \\ Correspondence to: Kwang Ha Yoo. 4-12 Hwayang, Gwanjin-gu, Konkuk University Medical Center, School of Medicine, Seoul, South Korea. \\ Email: khyou@kuh.ac.kr.
}

\begin{abstract}
The prevalence of chronic obstructive pulmonary disease (COPD) is high in South Korea which has remained virtually unchanged over the past few years. Other challenges related to COPD in South Korea include a low level of awareness of COPD, underutilization of pulmonary function tests (PFTs) and a low level of inhaler use. Continued efforts have been made to raise awareness of COPD in the general public and promote screening tests for the early detection of COPD patients for high-risk patients, which should be the primary object for better management of the disease. The Korean Academy of Tuberculosis and Respiratory Diseases (KATRD) and the Korea Disease Control and Prevention Agency (KDCA) have been working in tandem on numerous projects to resolve these issues. As the fruit of these efforts, a couple of projects are currently being carried out to add PFTs into the National Health Examination (NHE) of Korea as part of screening tests and improve the quality of COPD treatments in primary care settings. Raising public awareness of a chronic disease such as COPD requires collective efforts of academic societies and government. In addition, personalized education programs that are tailored to individual COPD patients is a necessity to raise adherence of treatment and self-management of COPD. The aim of this manuscript is to report the current status of COPD management in South Korea in hopes that it will help better treat and manage COPD in other nations coping with similar challenges.
\end{abstract}

Keywords: Chronic obstructive pulmonary disease (COPD); awareness; education; pulmonary function test (PFT); South Korea

Submitted Jan 27, 2021. Accepted for publication Jun 02, 2021.

doi: $10.21037 /$ jtd-21-172

View this article at: https://dx.doi.org/10.21037/jtd-21-172

\section{Introduction}

Chronic obstructive pulmonary disease (COPD) is a chronic inflammatory disease of the airways that requires a lifelong management (1). According to a survey conducted by the Korean Academy of Tuberculosis and Respiratory Diseases (KATRD) in 2008, using data from Korea National Health and Nutrition Examination Survey (KNHANES), people aged 40 years or over had the COPD prevalence rate of $13.4 \%$ regardless of history of smoking $(19.4 \%$ of men and $7.9 \%$ of women) (2). The KNHANES data show the results of nationwide, large-scale, cross-sectional surveys that are conducted by the Korea Disease Control and Prevention Agency (KDCA) and the Ministry of Health and Welfare $(\mathrm{MHW})$ with a complex, multistage probability sample 
Table 1 Prevalence of COPD and rate of diagnosis

\begin{tabular}{|c|c|c|c|c|c|c|c|c|c|}
\hline Variable & 2007 & 2008 & 2009 & 2010 & 2011 & 2012 & 2013 & 2014 & 2015 \\
\hline$\geq 40$ & 15.6 & 13.4 & 11.0 & 13.1 & 13.2 & 14.6 & 13.5 & 14.2 & 13.4 \\
\hline$\geq 65$ & 34.0 & 31.1 & 23.6 & 31.9 & 27.8 & 30.2 & 31.5 & 31.1 & 28.1 \\
\hline \multicolumn{10}{|c|}{ Age group, year } \\
\hline $50-59$ & 14.3 & 9.0 & 9.1 & 9.6 & 10.7 & 11.4 & 9.3 & 9.6 & 9.7 \\
\hline $60-69$ & 21.5 & 21.4 & 17.7 & 20.3 & 21.7 & 24.9 & 22.1 & 20.6 & 21.2 \\
\hline$\geq 70$ & 38.8 & 34.8 & 26.2 & 35.8 & 29.3 & 31.6 & 35.2 & 35.9 & 30.6 \\
\hline
\end{tabular}

Prevalence of COPD during the period from 2007 to 2015 (\%). COPD, chronic obstructive pulmonary disease.

extraction to represent the total population of all ages in South Korea. The KNHANES data include age, sex, height, weight, and self-reported smoking history as well as the results of spirometry tests using normal predictive values in Korean population (3).

The trends in the prevalence of COPD in South Korea using the same data have remained unchanged, which ranged from $13.1 \%$ to $14.6 \%$ during the period from the year of 2010 to 2015 (Table 1) (4). Among the total COPD patients, only less than $5 \%$ of patients visited hospitals in order to manage their COPD. According to Statistics Korea, often referred as KOSTAT, COPD is one of the ten major causes of death in South Korea, ranking the 7th leading cause of death (5). The World Health Organization (WHO) expects that the prevalence and mortality rates of COPD will continue to rise worldwide (6). The WHO also emphasizes the importance of the prevention, early diagnosis, and proper treatments of COPD and it selected COPD as 1 of the 4 non-communicable diseases that must be managed worldwide in 2018. In this review, we have updated the current status of COPD awareness, treatments, and strategies for COPD management in South Korea.

We present the following article in accordance with the Narrative Review reporting checklist (available at https:// dx.doi.org/10.21037/jtd-21-172).

\section{COPD awareness}

The prevalence of COPD is approximately $13 \%$ in people aged 40 years or over and approximately $30 \%$ in people aged 60 years or over in South Korea as the prevalence of the disease tends to increase with age (4). However, the COPD-related hospital visit rate of patients who visit hospitals to manage their COPD is less than $5 \%$ of the total COPD patients (4). The main reason why COPD-related hospital visit rate is very low is twofold: (I) a low level of awareness of COPD in the general population, and (II) a low rate of conducting PFTs for high-risk patients such as people aged 40 years or over with history of smoking. Heffler et al. and Caramori et al. suggest that one of the reasons underlying the low level of awareness of COPD is the underutilization of spirometry by general practitioners as part of the assessment of patients complaining dyspnea, despite all the major international COPD management guidelines mandate the use of spirometry in the initial diagnostic evaluation of patients with symptoms suggestive of COPD $(7,8)$. Raising awareness and understanding of COPD are important aspects of the disease management. However, there is scarce research on public awareness of COPD in South Korea. Mun et al. studied the awareness of COPD among the current smokers who smoke at least 10 packs of cigarettes per year, and the study conducted telephone interviews using a structured questionnaire throughout South Korea (9). The study found that $60.6 \%$ of subjects reported COPD-related symptoms, among which only $1.2 \%$ of subjects had been diagnosed with COPD and only $0.4 \%$ of subjects showed their awareness of COPD by way of spontaneously recognizing COPD as a respiratory disease. Seo et al. conducted a face-to-face interview with the heavy smokers who participated in a smoking-cessation program in South Korea in 2014 and the study found that only $1.0 \%$ of subjects were aware of the fact that COPD is a respiratory disease (10). Despite exhibiting COPD-related symptoms, most smokers were unaware of the fact that 
Table 2 Total estimated costs of COPD in Korea

\begin{tabular}{lcc}
\hline Category & Cost (million USD) & Percentage \\
\hline Direct medical & 206.9 & 16.6 \\
Formal & 44.2 & 3.5 \\
Informal & & \\
Direct non-medical & 4.3 & 0.3 \\
Transportation & 486.3 & 39.0 \\
Nursing & & \\
Indirect & 407.8 & 32.7 \\
Loss of productivity & 96.2 & 7.7 \\
Premature deaths & $1,245.6$ & 100 \\
Total & & \\
\hline
\end{tabular}

COPD, chronic obstructive pulmonary disease.

COPD is a respiratory disease. The level of awareness of COPD in South Korea was very low in the population with high risk of COPD such as smokers aged 40 and older.

It is obvious that a nationwide effort is needed to manage the patients with chronic airway diseases as the number of these patients is consistently on the rise due to various reasons including rapid urbanization, uncontrolled air pollution with increased exposure to fine dust particles, cigarette smoking, and increased life expectancy (11). Environmental risk factors can cause COPD symptoms to worsen and exposure to fine dust particles has been associated with increased hospital admission $(12,13)$. But often, people with COPD are not aware that they have the disease. Identification of undetected COPD patients plays an important role for self-management of COPD along with patient education programs. PFTs are effective methods to detect patients with COPD even in its very early stage, but the problem is that the rate of performing PFTs in primary care clinics in South Korea is very low; the rate is less than $20 \%$ (14). There are a great number of undetected COPD patients in South Korea. Hwang et al. recently conducted a field survey to assess COPD awareness and COPD prevalence among the current male smokers recruited from commuters and passers-by at a busy train hub in Seoul, South Korea (15). The study reported that approximately $28 \%$ of subjects who were current smokers had COPD and that a large proportion of participants showed a lack of knowledge about both COPD and PFTs. Hwang et al. also reported that optimistic bias related to COPD among the male current smokers. Participants perceived that they were about as likely to develop COPD as similarly aged nonsmokers and their friends (15). It is also well known from the Weinstein report that smokers tend to underrate personal health risks of cigarette smoking (16). Kim et al. reported that COPD was found in approximately $23 \%$ of the participants aged 40 years or over with more than 10 pack-year smoking history (17). This finding was consistent with the findings by Hwang et al. (15). The only difference between the studies of Hwang et al. and Kim et al. is smoking patterns of participants. Hwang et al. recruited current smokers as subjects while Kim et al. recruited ex- and current smokers, which is reinforcing the importance of active COPD casefinding for the high-risk population. Even for the patients who have preserved ratio impaired spirometry [PRISm; forced expiratory volume in 1 second (FEV1)/forced vital capacity (FVC) $>0.7$ with reduced FEV1 $<80 \%$ predicted], they are most likely to develop COPD $(18,19)$. Both raising awareness of COPD and increasing PFTs are important and necessary to manage and prevent the disease in the highrisk population.

Despite a high rate of under-diagnosed COPD, the economic burden of COPD is relatively high. Kim et al. reported that total COPD cost that include direct and indirect costs is approximately 1,245 million U.S. dollars in South Korea in 2015 (20) (Table 2). The total cost of COPD is less than that of other major chronic diseases such as hypertension, diabetes mellitus and asthma, but costs to individuals are higher in COPD patients than patients with other chronic diseases.

There are many ways to improve public awareness of COPD. Aside from identifying undetected COPD patients, education programs for existing patients and primary care physicians are also important. Well-organized education programs help increase knowledge about the disease and the knowledge improves quality of life as well as the levels of satisfaction for both patients and physicians (21). Continuous efforts to raise awareness of COPD in the general public by offering personalized education programs with various educational tools to COPD patients can eventually enhance public awareness of COPD and increase the rate of performing PFTs.

\section{Treatment status}

Inhaled long-acting bronchodilators (ILABs) are a cornerstone to treat stable COPD patients (1). A study reports that ILABs can help reduce hospital admissions for the patients who are newly diagnosed with COPD (22). 


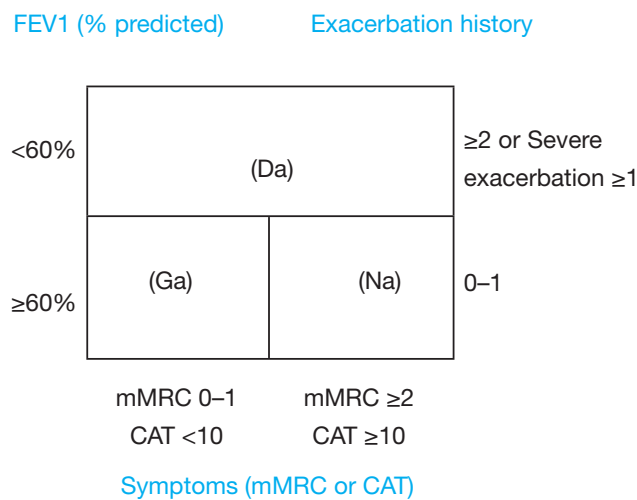

Figure 1 The classification of severity in Korea guideline. FEV1, forced expiratory volume in 1 second; mMRC, modified Medical Research Council; CAT, COPD Assessment Test.

The KATRD first published Korean national guidelines on COPD in 2005 which was most recently revised in 2018 (1). The KATRD guidelines have some differences compared to the 2020 Global Initiative for Chronic Obstructive Lung Disease (GOLD) guidelines (Figure 1). The GOLD introduced the $\mathrm{ABCD}$ tool, but the KATRD guidelines use a three-grading system by integrating GOLD group $\mathrm{C}$ and $\mathrm{D}$ into a new group named $\mathrm{Da}$. The reasons behind the decision were that a very small number of COPD patients in South Korea belong to GOLD group C (23) and that there has been some unresolved controversies over the differences in prognosis between patients in group B and C (24). Secondly, the Korean COPD guidelines use PFTs to assess patients and set FEV1 of $60 \%$ as a cut-off value. Lastly, the Korean COPD guidelines recommend dual bronchodilators of inhaled long-acting $\beta 2$ agonist (LABA) plus long-acting muscarinic antagonist (LAMA) as an initial treatment option for patients in the KATRD group named $\mathrm{Na}$ which is equivalent to the 2017 GOLD group B. The three-grading system with $\mathrm{Ga}, \mathrm{Na}$ and $\mathrm{Da}$ classification of the Korean COPD guidelines is useful to differentiate exacerbation risks depending on the classification (25). Kim et al. first reported that a nationwide pattern of COPDrelated drug prescriptions from the year of 2006 to 2010 in South Korea using the Korea Health Insurance Review and Assessment Service (HIRA) database (26). In South Korea, the HIRA data cover the complete medical health care utilization data for the nearly entire population of South Korea ( 99\%, >50 million people). The author reported that the prescription rate of ILABs was very low in primary and secondary care clinics compared to tertiary hospitals. Another important finding was the popular use of oral methylxanthine and beta-agonists throughout the study period. This finding reflects a low awareness of the importance of inhaler medications and an inadequate adherence to current treatment guidelines on COPD in real-world clinical practice in primary and secondary clinics. The second study using the same data was conducted to analyze the trends in costs and utilization of COPD medications from the year of 2008 to 2013 (27). This study found that oral medications such as methylxanthine and beta-agonists were still widely prescribed, while prescriptions for ILABs increased gradually during the study period in South Korea. In this study, methylxanthine was the most commonly prescribed COPD medication during the 6-year study period in South Korea. This reflects the fact that numerous strategies and guidelines by academic societies and government to implement qualified treatments in primary care clinics have not succeeded. Along with the low rate of performing PFTs, the low rate of prescription of inhaler medication poses a problem in South Korea.

In order to improve the quality of care for patients with COPD, the HIRA launched a COPD quality assessment program in 2014 and has been reporting the annual results of COPD quality assessment program every year. The first and second results were reported in 2015 and 2016, respectively. Compared to the results of the first report, the second report showed that the proportion of patients with prescription of inhaled LABA and LAMA increased by $9.8 \%$ and $8.7 \%$, respectively, and that the proportion of patients with oral medication prescription was decreased by $5.3 \%$ (28). Recently, Kim et al. reported the first, second and third results from May 2014 to April 2017. During the 3 consecutive years of nationwide quality assessment, the PFT test implementation and inhaled bronchodilator prescription rates improved (29). The quality assessment results are published annually by the HIRA and shared with healthcare institutions.

Kim et al. reported the results of whether respiratory experts who work in university hospitals would prescribe the guidelines-recommended treatments to their COPD patients, using the Korean COPD Subtype Study (KOCOSS) cohort data (30). The KOCOSS is an ongoing prospective cohort for investigating the phenotypes of the COPD patients enrolled in 52 tertiary referral hospitals in South Korea (31). The author reported a low rate of adherence $(61.5 \%$ for 2011 guidelines, $49.6 \%$ for 2017 guidelines) to the GOLD guidelines with regard to treatment of COPD patients, which shared similar 

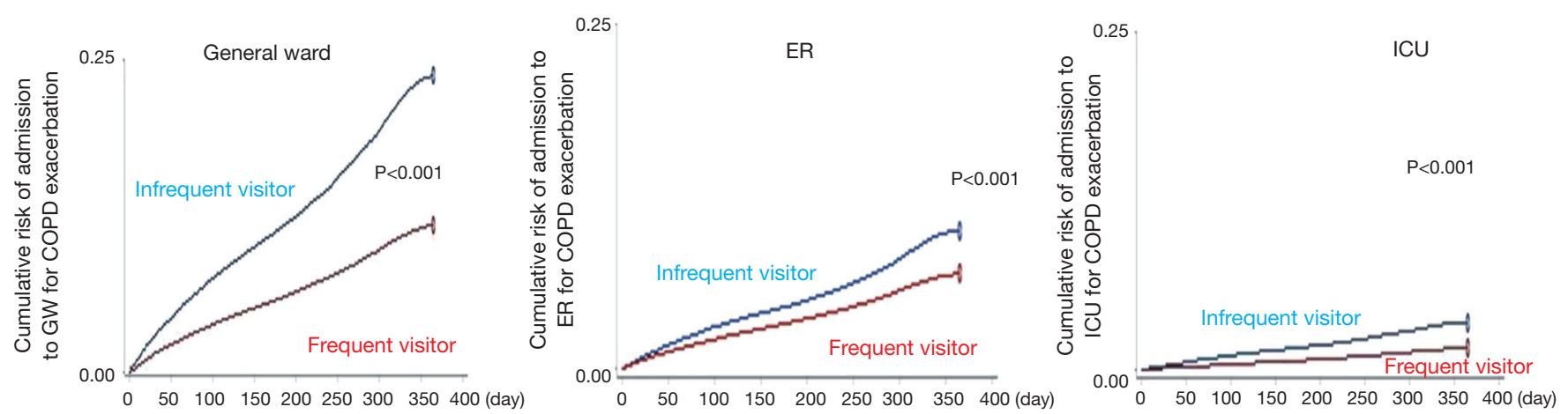

Figure 2 Kaplan-Meier graph showing the cumulative risk of admission to a GW, ER, ICU over time. GW, general ward; ER, emergency room; ICU, intensive care unit.

characteristics with the results of other studies (32-34). Inhaled corticosteroid (ICS)-containing regimen was found as the most commonly prescribed medication, which was inconsistent with the GOLD guidelines and this may indicate that even the COPD experts group does not adhere to the guidelines-recommended treatments.

Based on the HIRA data, Park et al. recently reported that frequent outpatient visits (three or more times per year) of COPD patients for COPD management can reduce the risk of exacerbations requiring admission by $45-60 \%$ (Figure 2) (35). The rate of reduction in exacerbation of COPD achieved in this study is much higher than that were reportedly achieved by use of ILABs in COPD $(15-30 \%)$. COPD is a chronic disease that requires patients to understand the nature of the disease, cooperate with their doctors, and manage the disease for a lifelong time. Frequent outpatient visits offer opportunities to COPD patients to keep their lung function and symptoms in check and under control, and improve their proper use of inhalers, and adjust their treatments in order to prevent acute exacerbations.

\section{Strategies to improve the management of COPD}

South Korea has several unmet needs with management of COPD patients such as a low level of the disease awareness, a low rate of PFTs for high-risk patients, a low prescription rate of ILABs and high economic burden of treatment costs in primary care clinics.

The low awareness of COPD and low rate of PFTs inevitably lead to under-diagnosis and under-treatment of COPD patients. Continued efforts should be carried out to increase awareness of COPD in the general population, health providers and COPD patients. Academic societies and government should be working in tandem to raise awareness of chronic diseases such as COPD so that the nationwide management of chronic diseases can be successful (36). Since 2013, the KATRD and the KDCA have been working closely to ensure an effective COPD management. In 2013, the KATRD submitted to the KDCA the total of thirty-eight COPD projects as part of strategies for management and prevention of COPD including early detection of COPD, improvement of awareness, increase prescription of inhaler therapy, reimbursement program for inhaler education, and national health insurance coverage for home/portable oxygen therapy and rehabilitation treatment in consideration of the urgency, importance, feasibility, and public interest of each project (37). At present, both the home/portable oxygen therapy, and the rehabilitation treatment qualify the Korean National Health Insurance coverage. Based on these proposed projects, the KATRD and the KDCA began conducting researches on effective methods of detect in mild COPD patients in 2014 and the KATRD proposed adding PFTs into the National Health Examination (NHE) program for people aged of 56 and over with history of smoking (38). In 2015, in cooperation with the KDCA, the KATRD developed educational materials targeting the high-risk population and primary care physicians. In 2016, the KATRD created three different types of COPD posters, which said "More frightening than lung cancer!, You should suspect COPD if you've been a smoker for more than 10 years" and "If you have respiratory symptoms, suspect COPD" (39). In 2016, the KATRD and the MHW launched a TV commercial for the first time to deliver a message to the public, saying "Stop smoking today, Otherwise no tomorrow" (40). In 2017, 
the KATRD began a project to get PFTs included as part of the NHE program (41). This project became the basis for the early detection of COOD patients in South Korea. The KATRD has an ongoing project that is set to build up a COPD registry from the year of 2018 to 2023 to assess various aspects of the disease including biomarkers and risk factors for COPD exacerbations, disease progression, mortality (42). A great deal of information expected from this project will provide a better insight into COPD management in real-world clinical practice.

An early diagnosis of COPD is very important as the disease is known to be irreversible in its later stages. In severe COPD patients, expenditure of medical costs is expected more than three times when compared to mild COPD patients, and most of the deaths occur in severe patients (43). Therefore, it is important for COPD patients to prevent the progression of the disease from mild into severe state through self-management such as smoking cessation and rehabilitation training along with medication treatments when necessary (44). Rhee et al. reported the natural course of mild COPD in South Kore based on merged data using both the KNHANES and the HIRA during the period of 6 years (45). The study showed that patients with mild COPD eventually used healthcare facilities, therefore the number of hospitalization and the mean medical costs per person increased annually. Even if these COPD patients had mild symptoms with a relatively good lung function, it is important to identify and manage these patients because the decline in FEV1 was higher in GOLD stage I and II patients compared with stage III and IV patients (46). Also, the patients with mild COPD have pathological and physiological changes with more systemic inflammation, more comorbidities and higher mortality compare to normal control even when the patients exhibited no symptoms. Even for the mild patients with more than $80 \%$ of predictive value of FEV1, a regular follow-up can reduce the socioeconomic burden of the disease (47).

Since 2017, the KATRD has been trying to add PFTs into the NHE program for the early detection of COPD patients among the high-risk population such as people with history of smoking and respiratory symptoms. The NHE program in South Korea is targeting the general population aged 40 years or over, who are eligible for the national health screening every other year for free of charge. When non-covered services are to be approved for the benefits of the NHE program of Korea, the following criteria must be met: major health issue, treatability with early detection, availability of ready-to-use screening tools, testing advantages outweighing disadvantages, and cost effectiveness. COPD meets all these requirements in South Korea. The KATRD proposed to conduct PFTs two times over a lifetime; the first testing at the age of 56 and second testing at the age of 66 with history of smoking. The corresponding incremental cost effectiveness ratio (ICER) was approximately forty thousand U.S. dollars, and it is lower than ICER with hypertension and diabetes mellitus. Screening testing for hypertension and diabetes mellitus is already part of the NHE (41). The mild COPD patients who are diagnosed by the NHE program should be able to get educated on smoking cessation, regular exercise, vaccination for influenza and pneumonia as well as the way how to reduce exposure to fine dust particles.

According to the COPD quality assessment program, only approximately $15 \%$ of the total COPD patients are being treated by primary care physicians (28). As part of the efforts to improve COPD management in primary care clinics, the KATRD has been relentless in trying to implement reimbursement programs for primary care clinics. The purpose of the project was to promote reimbursement for inhaler treatment and disease education in primary care clinics (48).

\section{Conclusions}

There have been numerous efforts by the KATRD over the years to improve the level of COPD knowledge in primary care settings that includes awareness of COPD, importance of inhaler treatment and management of COPD with clinical practice guidelines. The KATRD continue to make suggestions to government with various projects for the early detection of COPD patients. In recent years, the KATRD and the KDCA have been working together on many important projects to improve the management and prevention of COPD. Once PFTs gets included as part of the Korean NHE program for the high-risk population, it will be much easier to identify undetected COPD patients with mild symptoms. Aside from pharmacologic treatments, educational tools will be required for theses COPD patients. If the disease education programs for patients and primary care physicians become eligible for reimbursement, it will contribute to a significant improvement of treatment quality for the patients with COPD in primary care settings. The most effective management of COPD will be implemented when academic societies, government, and the general public all work together. 


\section{Acknowledgments}

Funding: None.

\section{Footnote}

Provenance and Peer Review: This article was commissioned by the Guest Editor (Ki-Suck Jung and Chin Kook Rhee) for the series "current epidemiology and policies of COPD worldwide" published in Fournal of Thoracic Disease. The article has undergone external peer review.

Reporting Checklist: The authors have completed the Narrative Review reporting checklist. Available at https:// dx.doi.org/10.21037/jtd-21-172

Conflicts of Interest: Both authors have completed the ICMJE uniform disclosure form (available at https:// dx.doi.org/10.21037/jtd-21-172). The series "current epidemiology and policies of COPD worldwide" was commissioned by the editorial office without any funding or sponsorship. The authors have no other conflicts of interest to declare.

Ethical Statement: The authors are accountable for all aspects of the work in ensuring that questions related to the accuracy or integrity of any part of the work are appropriately investigated and resolved.

Open Access Statement: This is an Open Access article distributed in accordance with the Creative Commons Attribution-NonCommercial-NoDerivs 4.0 International License (CC BY-NC-ND 4.0), which permits the noncommercial replication and distribution of the article with the strict proviso that no changes or edits are made and the original work is properly cited (including links to both the formal publication through the relevant DOI and the license). See: https://creativecommons.org/licenses/by-nc-nd/4.0/.

\section{References}

1. Park YB, Rhee CK, Yoon HK, et al. Revised (2018) COPD Clinical Practice Guideline of the Korean Academy of Tuberculosis and Respiratory Disease: A Summary. Tuberc Respir Dis (Seoul) 2018;81:261-73.

2. Yoo KH, Kim YS, Sheen SS, et al. Prevalence of chronic obstructive pulmonary disease in Korea: the fourth Korean National Health and Nutrition Examination Survey, 2008.
Respirology 2011;16:659-65.

3. Choi JK Paek D, Lee JO. Normal Predictive Values of Spirometry in Korean Population. Tuberc Respir Dis (Seoul) 2005;58:230-42.

4. Hwang YI, Park YB, Yoo KH. Recent Trends in the Prevalence of Chronic Obstructive Pulmonary Disease in Korea. Tuberc Respir Dis (Seoul) 2017;80:226-9.

5. The result of causes of death statistics in 2010. Daejeon: Statistics Korea, 2019.

6. Mathers CD, Loncar D. Projections of global mortality and burden of disease from 2002 to 2030. PLoS Med 2006;3:e442.

7. Heffler E, Crimi C, Mancuso S, et al. Misdiagnosis of asthma and COPD and underuse of spirometry in primary care unselected patients. Respir Med 2018;142:48-52.

8. Caramori G, Bettoncelli G, Tosatto R, et al. Underuse of spirometry by general practitioners for the diagnosis of COPD in Italy. Monaldi Arch Chest Dis 2005;63:6-12.

9. Mun SY, Hwang YI, Kim JH, et al. Awareness of chronic obstructive pulmonary disease in current smokers: a nationwide survey. Korean J Intern Med 2015;30:191-7.

10. Seo JY, Hwang YI, Mun SY, et al. Awareness of COPD in a high risk Korean population. Yonsei Med J 2015;56:362-7.

11. Song WJ, Wong GWK. Changing trends and challenges in the management of asthma in Asia. J Allergy Clin Immunol 2017;140:1272-4.

12. Hong Y, Lim MN, Kim WJ, et al. Influence of environmental exposures on patients with chronic obstructive pulmonary disease in Korea. Tuberc Respir Dis (Seoul) 2014;76:226-32.

13. Jo YS, Lim MN, Han YJ, et al. Epidemiological study of $\mathrm{PM}(2.5)$ and risk of COPD-related hospital visits in association with particle constituents in Chuncheon, Korea. Int J Chron Obstruct Pulmon Dis 2018;13:299-307.

14. Choi JY, Yoon HK, Lee JH, et al. Current status of asthma care in South Korea: nationwide the Health Insurance Review and Assessment Service database. J Thorac Dis 2017;9:3208-14.

15. Hwang YI, Park YB, Yoon HK, et al. Male current smokers have low awareness and optimistic bias about COPD: field survey results about COPD in Korea. Int J Chron Obstruct Pulmon Dis 2019;14:271-7.

16. Weinstein ND. Accuracy of smokers' risk perceptions. Ann Behav Med 1998;20:135-40.

17. Kim JK, Lee CM, Park JY, et al. Active case finding strategy for chronic obstructive pulmonary disease with handheld spirometry. Medicine (Baltimore) 2016;95:e5683.

18. Park HJ, Byun MK, Rhee CK, et al. Significant predictors 
of medically diagnosed chronic obstructive pulmonary disease in patients with preserved ratio impaired spirometry: a 3-year cohort study. Respir Res 2018;19:185-96.

19. Wan ES, Fortis S, Regan EA, et al. Longitudinal Phenotypes and Mortality in Preserved Ratio Impaired Spirometry in the COPDGene Study. Am J Respir Crit Care Med 2018;198:1397-405.

20. Kim C, Kim Y, Yang DW, et al. Direct and Indirect Costs of Chronic Obstructive Pulmonary Disease in Korea. Tuberc Respir Dis (Seoul) 2019;82:27-34.

21. Lee JY, Yoo KH, Kim DK, et al. Effects of Educational Interventions for Chronic Airway Disease on Primary Care. J Korean Med Sci 2016;31:1069-74.

22. Kim J, Kim K, Kim Y, et al. The association between inhaled long-acting bronchodilators and less in-hospital care in newly-diagnosed COPD patients. Respir Med 2014;108:153-61.

23. Song JH, Lee CH, Um SJ, et al. Clinical impacts of the classification by 2017 GOLD guideline comparing previous ones on outcomes of COPD in real-world cohorts. Int J Chron Obstruct Pulmon Dis 2018;13:3473-84.

24. Cabrera López C, Casanova Macario C, Marín Trigo JM, et al. Comparison of the 2017 and 2015 Global Initiative for Chronic Obstructive Lung Disease Reports. Impact on Grouping and Outcomes. Am J Respir Crit Care Med 2018;197:463-9.

25. Hwang YI, Park YB, Oh YM, et al. Comparison of Korean COPD guideline and GOLD initiative report in term of acute exacerbation: a validation study for Korean COPD guideline. J Korean Med Sci 2014;29:1108-12.

26. Kim C, Yoo KH, Rhee CK, et al. Health care use and economic burden of patients with diagnosed chronic obstructive pulmonary disease in Korea. Int J Tuberc Lung Dis 2014;18:737-43.

27. Lee J, Lee JH, Kim JA, et al. Trend of cost and utilization of COPD medication in Korea. Int J Chron Obstruct Pulmon Dis 2016;12:27-33.

28. Chung SM, Lee SY. Evaluation of Appropriate Management of Chronic Obstructive Pulmonary Disease in Korea: Based on Health Insurance Review and Assessment Service (HIRA) Claims. Tuberc Respir Dis (Seoul) 2017;80:241-6.

29. Kim KY, Yoo KH, Choi HS, et al. Nationwide quality assessment of treatment for chronic obstructive pulmonary disease. J Thorac Dis 2020;12:7174-81.

30. Kim TO, Shin HJ, Kim YI, et al. Adherence to the GOLD Guideline in COPD Management of South Korea: Findings from KOCOSS Study 2011-2018. Chonnam
Med J 2019;55:47-53.

31. Lee JY, Chon GR, Rhee CK, et al. Characteristics of Patients with Chronic Obstructive Pulmonary Disease at the First Visit to a Pulmonary Medical Center in Korea: The KOrea COpd Subgroup Study Team Cohort. J Korean Med Sci 2016;31:553-60.

32. Turan O, Emre JC, Deniz S, et al. Adherence to Current COPD Guidelines in Turkey. Expert Opin Pharmacother 2016;17:153-8.

33. Palmiotti GA, Lacedonia D, Liotino V, et al. Adherence to GOLD guidelines in real-life COPD management in the Puglia region of Italy. Int J Chron Obstruct Pulmon Dis 2018;13:2455-62.

34. Jochmann A, Scherr A, Jochmann DC, et al. Impact of adherence to the GOLD guidelines on symptom prevalence, lung function decline and exacerbation rate in the Swiss COPD cohort. Swiss Med Wkly 2012;142:w13567.

35. Park HJ, Byun MK, Kim T, et al. Frequent Outpatient Visits Prevent Exacerbation of Chronic Obstructive Pulmonary Disease. Sci Rep 2020;10:6049.

36. Kinnula VL, Vasankari T, Kontula E, et al. The 10year COPD Programme in Finland: effects on quality of diagnosis, smoking, prevalence, hospital admissions and mortality. Prim Care Respir J 2011;20:178-83.

37. Yoo KH. The strategies for prevention and control of COPD. KDCA, 2013.

38. Jung KS. Effective models of finding and mediating COPD patients with early and mild disease. KDCA, 2014.

39. Park YB. Development of strategies of customized campaign toolkit for COPD high risk population. KDCA, 2016.

40. K-tips for cessation of smoking [database on the Internet]. Korea Health Promotion Institute. 2017. Available online: https://youtu.be/84gqro2rjQ8

41. Kim YH. Effectiveness and cost-effectiveness analysis of the national screening program of pulmonary function for the purpose of smoking cessation and health promotion. KDCA,2020.

42. Yoo KH. Establishment of registry for COPD Patients. KDCA, 2018.

43. Kim J, Rhee CK, Yoo KH, et al. The health care burden of high grade chronic obstructive pulmonary disease in Korea: analysis of the Korean Health Insurance Review and Assessment Service data. Int J Chron Obstruct Pulmon Dis 2013;8:561-8.

44. Yoo KH. Smoking cessation and chronic obstructive pulmonary disease. Korean J Intern Med 2015;30:163-6.

45. Rhee CK, Kim K, Yoon HK, et al. Natural course of early 
COPD. Int J Chron Obstruct Pulmon Dis 2017;12:663-8.

46. Tantucci C, Modina D. Lung function decline in COPD. Int J Chron Obstruct Pulmon Dis 2012;7:95-9.

47. Lee YS, Min KH, Rhee CK, et al. The Economic Effect of Early Management in Patients with Early Chronic

Cite this article as: Park YB, Yoo KH. The current status of chronic obstructive pulmonary disease awareness, treatments, and plans for improvement in South Korea: a narrative review. J Thorac Dis 2021;13(6):3898-3906. doi: 10.21037/jtd-21-172
Obstructive Pulmonary Disease: Results from a PopulationBased Nationwide Survey. Lung 2019;197:303-13.

48. Yoo KH. Primary care-oriented adult asthma.COPD management model development research. National Health Insurance Service, 2020. 